Information Management and Business Review

Vol. 3, No. 1, pp. 1-7, Jul 2011 (ISSN 2220-3796)

\title{
Paths to Success for 7-Eleven in Thailand
}

\author{
Thanee Ngaochay*, John Walsh \\ School of Management, Shinawatra University, Phayathai, Bangkok 10400 Thailand \\ *thanee2304@gmail.com
}

\begin{abstract}
This paper reports on an empirical study aimed at elucidating reasons for success in the implementation of strategic decisions by 7-Eleven in Thailand. The 7-Eleven convenience store is a business format franchising operation, which includes the product or service, the brand name or trademark, and the operating system developed by the franchisor and it has experienced significant growth. The Charoen Pokphand (CP) All Public Company Limited (PCL) is the operator of the 7-Eleven convenience stores in Thailand and it has been involved, therefore, with creating opportunities in the franchise system for that market. Potential franchisors have staff trained and support provided for all aspects of their businesses. To have better chances for success, 7-Eleven needs to evaluate itself in order to improve its systems. People are one key success factor in the franchise business, particularly in terms of the representative of the franchisor, who as an agent of the company reflects the company's image. For the company to achieve sustainable growth, emphasis should be placed on organizational and human resource development. Both parties in the business must provide high levels of cooperation to each other. The franchise business is a special relationship in which the parties can mutually share the benefits.
\end{abstract}

Keywords: Success Factors, Franchise, Convenience Stores, Thailand

\section{Introduction}

Charoen Pokphand (CP) All Public Company Limited (PCL) is the operator of the 7-Eleven convenience stores which have been active in the Thai economy for some two decades. The Company is the sole operator of 7-Eleven in Thailand and has been granted an exclusive right to this end from 7-Eleven, Inc., USA, to conduct business under the Area License Agreement. It operates, therefore, a network of stores that covers nearly every area of the country and offers a wide and growing array of products and services in those stores CP ALL PCL, 2008, 2009). The Company attempts to position itself as the convenience store brand that is lodged in the hearts of the Thai people through developing and selecting new products and services to provide greater levels of customer satisfaction. With regard to product strategy, the Company focuses on drinks and ready-to-eat food and beverages. To highlight its strength as a convenience food store, the Company implemented the "7-Eleven Ready-to-Eat Food Campaign" as a means of appealing to a Thai society that is in transition from historical to modern forms of existence which now feature lower levels of communal living and eating and greater propensity for people in urban locations to live independent lives. Life, according to the advertising campaign, is now constantly lived in a rush. The company wishes constantly to expand the number of its branches in Bangkok and its suburbs and the other provinces of Thailand, in conditions of increasingly intense competition in the convenience store sector and seemingly approaching saturation point. Its intention is to maintain business stability and growth while at the same time mobilizing organization development (OD) and human resource development (HRD) to improve staff and operating processes. This it has been able to accomplish through normal procedures such as setting targets and establishing financial security and systematic operations for management in line with standards set for the National Quality Award.

These successes have been reasonable due to the purpose, knowledge, and capabilities of all employees at every level. The concentrated efforts of all employees working in agreement, combining similarities and differences will drive effective thinking and working together and will finally lead to the ability to create continued strength for the Company. Moreover, the Company will focus on building an organizational culture to create competitive advantage to meet customers' demands through differentiated products and services. In addition, this will also promote the create talents of the employees and improve the quality of employees to be more effective. The success and stability of CP All today will be an important foundation in building future business sustainability. Net profit has increased from 1,460 million Baht in 2007 to 4,992 million Baht in 2009. The convenience store is relatively resistant to the reduction in demand caused by economic downturns, such as that caused by the 2008-9 global financial crisis, since many of its products act 
as substitutes for more expensive alternatives. The 7-Eleven Stores are categorized into three types based on ownership as follows:

Table 1: Types of 7-Eleven Stores

\begin{tabular}{lccccc}
\hline (Unit: stores) & $\mathbf{2 0 0 6}$ & $\mathbf{2 0 0 7}$ & $\mathbf{2 0 0 8}$ & $\mathbf{2 0 0 9}$ & $\begin{array}{c}\text { No. of New Stores } \\
\text { Opening in 2009 }\end{array}$ \\
\hline Corporate Stores & 2,119 & 2,462 & 2,671 & 2,794 & 123 \\
Franchise Stores & 1,449 & 1,562 & 1,813 & 2,130 & 317 \\
Sub-Area License Stores & 216 & 255 & 294 & 346 & 52 \\
Total & 3,784 & 4,279 & 4,778 & 5,270 & 492 \\
\hline
\end{tabular}

Source: Adapted from Annual Report 2009, CP ALL PCL

These categories may be described as follows;

- Corporate Stores are wholly owned and managed by the company which invests in the necessary retailing equipment, store decorations and inventory.

- Franchise Stores offer opportunities for people wishing to operate their own store under the franchising system. Again, the company invests in the necessary retailing equipment, store decorations and inventory.

- Sub-Area License Stores involve sub-area license agreements with third parties, who operate 7Eleven stores in territory in which sub-area licensees themselves will be responsible for store management, while the Company will provide assistance and support under agreed conditions

As the Thai market approaches saturation, it is apparent that 7-11 stores will be better positioned to increase profitability in the long run through increased productivity and that this will be achieved, if at all, through HRD methods. Hence, it is important to determine the means by which it might appear that such development might take place and that is the purpose of this paper. The paper is organized according to a conventional format: after this introduction, a literature review discusses relevant contributions in the area of investigation and this is followed by the methodology, findings and recommendations sections

The specific purpose of this paper is to identify the strategy of 7-11 franchise stores in Thailand with a view to understanding key success factors in that strategy, if any. Armed with this knowledge, it will then be possible to determine the extent to which such success factors might be transferable to other operations.

\section{Literature Review}

Franchising: Franchises are business forms in which a brand owner (franchisor) rents, usually on an exclusive or semi-exclusive basis, some aspects of the branded property to an individual or organization (franchisee) in return for a fee and royalties. Negotiations between the two parties determine the nature of division of labour and expenditure of all other aspects of the business offering concerned. Franchising has taken place for hundreds of years and probably originated in the relationship between breweries and public houses in the UK. The structure and quality of the relationship between franchisor and franchisee can be crucial in determining business success and profitability. An unsuccessful relationship in either structure or quality can result in failure or, at least, dissatisfaction with the business proposition. In a traditional, hierarchical franchisor operation, contractual obligations delineate the relationship and, in Hofstedian terms, ambiguity is minimized (Lafontaine, 1993). By contrast, network franchise operations are more open to two-way interactions and supportive communication modes (Achrol, 1997). The latter form appears to offer certain benefits in contemporary management styles and particularly in the case of developing Thailand, where management generally benefits from regular means of communication and interaction with other stakeholders. However, there may be structural, ideological or personal reasons of why the flow of information between the partners may be sub-optimal and, therefore, a cause of potential failure (Paswan and Wittmann, 2009). This is problematic since it is becoming increasingly clear that sustainable profitability in a franchise operation depends not so much on the product offering as the business model that can be obtained and nurtured (Hall and Dixon, 1988).

However, it should be borne in mind that franchisor and franchisee are likely to be at different stages in their learning cycles and to have different expectations concerning the length of the relationship and its ultimate value. Owing to the transaction costs involved in learning and mutual adaptation, it is likely that the franchisor will have a longer-term perspective than a franchisee might have, especially if that franchisee is a young individual hoping to acquire managerial experience and expertise through a limited term contract. The issue of differential expectations is compounded when, as has often been the case in the past, the 
relationship between the two parties is represented by a hierarchical, quantified nature (as in, for example, Klein, 1995). Some research indicates a differential level of inter-partner disputes depending on the stage of the life cycle reached (Frazer, 2001). In terms of the selection of a franchise partner, comparatively little research exists in comparison with the copious amounts of literature dealing with the selection of a joint venture partner. One notable exception (Altinay, 2005) indicates that both personal and task-specific attributes should be considered in order to obtain a rounded evaluation of the selection process. Somewhat underlining the lack of research in this area, Doherty (2009) proposes a conceptual framework crossreferencing strategic and opportunistic factors as being relevant in the decision-making processes.

From the internationalization perspective, the research tends to have portrayed franchising as an alternative form of contractual arrangement that could be used by a company seeking to expand overseas alongside other market entry modes (Walsh, 2010). In a developing country such as Mexico, which has some relevant similarities with Thailand, the process of franchising as a mode of internationalization follows the kinds of strategic processes, which might be, anticipated (Teegen, 2000). However, as is common with many aspects of managerial research, it has proved prudent to adopt an eclectic approach to the issue, indicating for example that both incentives and resource constraint issues might be considered useful for understanding the motivations for the range of actors involved (Lafontaine and Kaufmann, 1994). This may also be seen in the consideration of the number of franchise agreements that are made within a specific territory (Rysman, 2001). In short, franchising is an area of managerial endeavour that has not yet been fully explored in the literature as a specific and characteristic branch but, rather, as one similar mode of entry or of operation among many others. The result of this is that it is not yet clear how successful franchise development can take place in a particular market beyond what might be recommended to any other business in a similar product category but different ownership structure.

Human Resource Development: Human resource development (HRD) involves various procedures aimed at improving the work-based productivity of people working in an organization. The range of activities and circumstances that might be involved in this practice is so great and diverse that HRD scholars and practitioners have struggled to find an appropriately encompassing definition (Chalofsky, 1992; Lucas and Deery, 2004). Nevertheless, the practice of HRD has matured to the extent that strategic human resource management, which takes a large-scale and long-term view of the possibilities of use and development of human resources to obtain and sustain competitive advantage (Lengnick-Hall et al., 2009). However, the conceptual approach seems to be better developed at the level of larger companies rather than for small and medium-sized enterprises (SMEs). One issue is that SMEs are defined differently in early every country. Second, the difference between companies at the low end of the scale to one of the larger medium-sized companies can be quite significant. In a country such as Thailand, for example, the great majority of businesses are in fact micro-operations with zero or a small number of employees and the horizons that such businesses have are quite different from comparatively large manufacturing or service provision firms. Unfortunately, research in this area tends to focus on the effort to marry micro-level operations to the lessons and contingencies of lessons drawn from analysis of large organizations (e.g. Wright and Boswell, 2002).

The 7-Eleven shops are also small operations, with generally no more than a handful of staff and many of them casual or semi-casual in nature. In some ways, the franchises may be seen as family businesses rather than conventionally-run businesses. It is certainly the case that, owing perhaps to the low levels of employment in such firms, few studies have considered the nature of HRD in such an environment (Runyan and Droge, 2008). Studies of comparable businesses in other Mekong region business environments have also indicated the preference of business owners for employees who are 'trustworthy,' where trustworthy tends to mean either a family member or, at least, someone already known to the business operator (Southiseng and Walsh, 2010; Southiseng and Walsh, 2011; Southiseng et al., 2008). In those studies, the main impediments to business success were identified as lack of access to capital and knowledge, increasingly competitive environment with additional entrants and customers interested primarily in price. Inspection of 7-Eleven and other convenience stores suggests that these characteristics are to some extent true also in Thailand. It is proposed that success, in the context of this research, be defined as the ability to complete the franchise contract and to provide the capability of moving ahead profitably with further contracts, if desired. 


\section{Research Methodology}

This project used a combination of different methods: interviews were conducted with a senior executive of CP All PCL and other policy-makers on a face-to-face basis using a semi-structured interview agenda designed to permit the conversation to flow in to areas of interest, rather than being forced into subjects that possibly represent the inappropriate preconceptions of the interviewer. Additional interviews were conducted with 7-Eleven managers and staff on a semi-formal or informal basis and the information gained supplemented by observation of relevant stores over a period of several months. Finally, the research was informed by study of secondary data, including annual reports. Interview transcripts (translated from the original Thai) and research observations, together with the secondary literature, were subjected to a process of content analysis according to recognized academic procedures (Kondracki and Wellman, 2002). The data obtained were processed, condensed, structured and arranged for analysis (Schilling, 2006). In common with the qualitative research approach in general, this research project placed the data first and centre and, from immersion in the data, it is hoped that theory will eventually emerge.

\section{Findings and Analysis}

CP All PCL believes that franchising in Thailand will expand in the future. This was why it decided to find suitable opportunities to franchise in the Kingdom and 7-Eleven seemed to be an obvious choice. This was not considered to be a very large investment upfront but, rather, demonstration of a level of commitment between the franchisor and franchisee. When deciding where to locate a new store, the company and its own franchisees pay attention to the local environment and the location of nearby residential units, as well as possible hospitals, schools markets and bus stations. The company details relevant staff to study and analyze the market environment which potential franchisees have identified as being a suitable location. So far, more than 5,000 branches have been opened and only a little over 400 subsequently closed down, which represents a very high success rate and indicates the quality of the initial evaluation. Principal reasons for closing down stores were trouble or dispute with the franchisee or else some change in the environment of the store, such as changes to the bus stops or bus stations near the location. There have also been issues with political uncertainty over the past few years because that political uncertainty has been very commonly associated with often lengthy street protests which can have a significant impact upon the number of customers willing or able to visit a shop in the area. Other issues that have become important include laws and regulations, both existing and in terms of possible changes, relating to such issues as foreign ownership of businesses, zoning requirements, customer and competition issues. In recent years, various changes to the laws concerning sales of cigarettes and alcohol, for example, have had significant impacts on product assortments and sales and the changes are often brought in at short notice and without any meaningful consultation. This has negatively affected growth, although the company feels it has been able to cope with the issues so far.

Emphasis and Prioritization of HRD: The Company believes that it is innovation, which drives future growth and commercial success in the market. This involves the constant development of new and tailor-designed goods and services for offer through 7-Eleven stores and hence the creation of new forms of competitive advantage. One notable example in this case is that of Singapore, where convenience stores including 7 Eleven offer a wide range of services, including payments of utilities and provision of travel tickets and top ups for electronic payment systems. Providing comparable services would require additional staff training and infrastructure investment. To enlist the support of franchise partners and their staff, the company has established both the President's Award Project and the Big Crowd of Fish project to encourage those people to submit their own ideas for new products based on their interaction with customers and other stakeholders. It is hoped that these schemes will bear valuable fruit in the future.

The company claims to support HRD and is involved with bilateral education systems organized in conjunction with the Office of the Vocational Education Commission. The strategy behind this approach involves such measures as offering distinct career paths through promotions, as well as providing incentives in the form of cash or in possible overseas trips. Additionally, a continuous series of dharma (Buddhist doctrine) lectures is offered to help people from a spiritual basis. This process has led to the establishment of the Panyawpiwat Technological Business School, which offers vocational education and both undergraduate and graduate level degrees. Affiliated schools access content via video conference technology and now more than 30 private vocational schools and involved in the network and are located not just in Bangkok and its vicinity but in many other provinces as well. The company also offers opportunities to franchisees to recruit staff for them, if they are unable to do so for themselves. All new staff members must 
pass the standard CP training procedure before they can be employed. It is believed that CP standards are higher than those of competing firms in this sector and personal observation and anecdote lends limited support to this notion.

Product Mix: A marketing team is constantly active in determining and judging new products based on continual assessment on customer behaviour and taste, both in the present and the possible future. The current product assortment consists primarily of food and beverage items (73\%) as well as a variety of non food items (not including prepaid phone cards). Alliance partners have been contracted and the resultant range of payment services includes 685 separate items. An online payment now offers numerous new opportunities as well. These services trade on the need for customer convenience and are based on understanding of existing consumer behaviour. The in-store services are supplemented by attached ATMs from a variety of banks in 4,300 branches and these machines also offer an increasing range of products, including life assurance and catalogue ordering. Many of these services are, clearly, aimed at people who do not have reliable internet service at home. Additionally, the internet infrastructure in Thailand is not currently very consistent and the level of trust in online transactions is comparatively low. The 7-Eleven shops may be offering an additional layer of trust through its reputation as a means of countering the low inherent level of trust.

Public Activities: The company supports the use of dharma in its HRD generally and links ethical behaviour in general living with behaviour as an employee or manager. Actions are divided, therefore, into those which are moral and those which are not. Rules and regulations imposed by the company follow the same approach in that employees are encouraged to think that obeying these regulations is equivalent to ethical or moral behaviour. To support this belief, the company enforces penalties on transgressors who may find their contracts cancelled in the event of unacceptable behaviour and it deploys teams acting as compliance officers to back up its threats. Corporate standards are insisted upon in every franchised store. By contrast, a project organized in concert with the Department of Internal Trade involves a program of seminars aimed at providing better knowledge of retail business development to eligible managers. In addition to these activities, the company also maintains the corporate social responsibility program that is expected of all firms these days and works under the motto 'because we are part of Thai society.' Various projects are associated with this.

Success Factors: Success factors that have been identified for 7-Eleven convenience stores include good management processes and procedures, effective communication and collaboration among partners and stakeholders. These processes must be evident both in the head company and also in individual franchised stores. Competitive advantage is sought through new product development and by the management of used products and surplus inventory. Additionally, the company has sought to differentiate its brand image through superior external cleaning and maintenance of stores. In terms of HRD, the company's success is based on shared learning opportunities, enhanced training in terms of product and safety management and capturing employees' knowledge about customers and possible new products available for them. Managers are provided with opportunities to expand their activities and to develop their personal networks of contacts. Retailing of basic or convenience products in an intensely competitive market relies to a certain extent upon the quality of service and the product assortment but more so, on the location of the store. In a sector with slender margins and at a time of economic downturn, it can quite literally be a question of a couple of metres here and there which make the difference between profitability and failure. That only $5 \%$ of CP's stores have folded after being established suggests that it is in the initial location function that the most important success factor is located and that only subsidiary (although still important) efforts are expended on other aspects of the business.

Transferability of Success Factors and Local Implications: As mentioned in the introduction, one of the principal objectives of this paper is not just to identify the key success factors but to assess the extent to which they are transferable across other business operations. It must be assumed that the success factors identified here are all transferable to quite a significant extent. 7-11 methods are quite transparent in nature and it is evident that comparable systems exist in other franchise operations available in Thailand. The Auntie Anne's soft pretzel franchises have become common in the shopping malls of urban Thailand and also offer training and sharing systems within a defined framework of managerial options. There are, on the other hand, differences in connection with the relationship with new product development and use, since the retail chains are constantly involved in negotiating with new opportunities for distribution from local companies who may be assumed to have a good grasp on local taste and retail criteria. That is different for companies which manufacture their own products. Nevertheless, the managerial component of this 
procedure is approximately similar. It is hoped that the skills and competencies that individuals might learn from working with 7-11 or from studying it will be used in the domestic economy to create not just home companies but new jobs and value adding retail chains. Previous franchise operators should not open operations in direct competition with their previous employers but there is plenty of scope for improving customer service-based businesses throughout the Kingdom and this might take place in a wide range of sectors.

\section{Conclusion}

Convenience stores such as 7-Eleven generally represent employment stepping stones for low salaried individuals who may skip from job to job in line with changing lifestyle priorities (e.g. educational career or family affairs). While insisting on passing initial training requirements might represent something of a barrier to exiting the company (and possibly also to entry), it is evident that company management sees development of efficient management procedures within stores as being, after the location decision, the best means of trying to ensure profitability. HRD is seen as important but in a subaltern position to efficiency of processes. Indeed, given the move to online services and greater use of electronic transactions, the elimination of costs associated with human assistants seems to be a feasible long-term goal for the company. This is in line with retailing in developing countries more generally, as the low productivity of excessive numbers of low salaried individuals comes to be seen as an impediment to growth rather than a spur to it.

\section{References}

Achrol, R. S. (1997). Changes in the Theory of Inter-organizational Relations in Marketing: Toward a Network Paradigm. Journal of Academy of Marketing Science, 25(1), 56-71.

Altinay, L. (2005). Factors Influencing Entry Mode Choices: Empirical Findings from an International Hotel Organization. Journal of Hospitality and Leisure Marketing, 12(3), 5-28.

Chalofsky, N. (1992). A Unifying Definition for the Human Resource Development Profession. Human Resource Development Quarterly, 3(2), 175-82.

CP ALL PCL. (2009). Annual Report 2008. Bangkok: CP ALL.

CP ALL PCL. (2010). Annual Report 2009. Bangkok: CP ALL.

Doherty, A. M. (2009). Market and Partner Selection Processes in International Retail Franchises. Journal of Business Research, 62(5), 528-34.

Frazer, L. (2001). Causes of Disruption to Franchise Operations. Journal of Business Research, 54(3), $227-34$.

Hall, P. \& Dixon, R. (1988). Franchising. London: Pitman Publishing.

Klein, B. (1995). The Economics of Franchise Contracts. Journal of Corporate Finance, 2(1-2), 9-37.

Kondracki, N. L. \&. Wellman, N. S. (2002). Content Analysis: Review of Methods and Their Applications in Nutrition Education. Journal of Nutrition Education and Behavior, 34(4), 224-30.

Lafontaine, F. \& Kaufmann, P. J. (1994). The Evolution of Ownership Patterns in Franchise Systems. Journal of Retailing, 70(2), 97-113.

Lafontaine, F. (1993). Contractual Agreements as Signaling Devices: Evidence from Franchising. Journal of Law, Economics, and Organization, 9(2), 256-289.

Lengnick-Hall, M. L., Lengnick-Hall, C.A., Andrade L.S. \& Drake, B. (2009). Strategic Human Resource Management: The Evolution of the Field. Human Resource Management Review, 19(2), 64-85.

Lucas, R. \& Deery, M. (2004). Significant Developments and Emerging Issues in Human Resource Management. International Journal of Hospitality Management, 23(5), 459-72.

Paswan, A. K. \& Wittmann, M. C. (2009). Knowledge Management and Franchise Systems. Industrial Marketing Management, 38(2), 173-180.

Runyan, R. C. \& Droge, C. (2008). A Categorization of Small Retailer Research Streams: What Does It Portend for Future Research? Journal of Retailing, 84(1), 77-94.

Rysman, M. (2001). How Many Franchises in a Market? International Journal of Industrial Organization, $19(3-4), 519-42$.

Schilling, J. (2006). On the Pragmatics of Qualitative Assessment: Designing the Process for Content Analysis. European Journal of Psychological Assessment, 22(1), 28-37.

Southiseng, N. \& Walsh, J. (2010). Competition and Management Issues of SME Entrepreneurs in Laos: Evidence from Empirical Studies in Vientiane Municipality, Savannakhet and Luang Prabang. Asian Journal of Business Management, 2(3), 57-72.

Southiseng, N. \& Walsh, J. (2011). Study of Tourism and Labour in Luang Prabang Province, Journal of Lao Studies, 2(1), 45-65. 
Southiseng, N., Ty, M., Walsh, J. \& Anurit, P. (2008). Development of Excellent Entrepreneurs in Small and Medium Enterprises in Laos and Cambodia. GMSARN International Journal, 2(4), 147-156.

Teegen, H. (2000). Examining Strategic and Economic Development Implications of Globalizing through Franchising. International Business Review, 9(4), 497-521.

Walsh, J. (2010). The Market Entry Decision and Success. Saarbrucken: Lambert Academic Publishing.

Wright, P. M. \& Boswell, W. R. (2002). Desegregating HRM: A Review and Synthesis of Micro and Macro Human Resource Management Research. Journal of Management, 28(3), 247-76. 